\title{
Seasonal variations in amplitudes and resonance frequencies of the HVSR amplification peaks linked to groundwater
}

\author{
Alexis Rigo ${ }^{\bullet},{ }^{1}$ Efthimios Sokos,${ }^{2}$ Valentine Lefils ${ }^{1}$ and Pierre Briole ${ }^{\oplus 1}$ \\ ${ }^{1}$ Laboratoire de Géologie, UMR8538, ENS, CNRS, PSL University, 24 rue Lhomond, 75005 Paris, France. E-mail: alexis.rigo@ens.psl.eu \\ ${ }^{2}$ Department of Geology, Seismological Laboratory, University of Patras, 26504, Rio, Greece
}

Accepted 2021 March 2. Received 2021 February 12; in original form 2020 May 5

\begin{abstract}
SUMMAR Y
Following the installation of a temporary seismological network in western Greece north of the Gulf of Patras, we determined the quality of the sites of each of the 10 stations in the network. For this, we used the horizontal-to-vertical spectral ratio (HVSR) method and calculated an average curve over randomly selected days between 0 and $10 \mathrm{~Hz}$. The daily HVSR curve is determined by the HVSR 12-hr calculation ( $1 \mathrm{hr}$ every two) without distinction between seismic ambient noise and earthquake signal. The HVSR curves obtained can be classified in three categories: flat curves without amplification, curves with a amplification peaks covering a large frequency range, and curves with one or more narrow peaks. In this third category $\mathrm{C} 3$, one station has one peak, two have two and one has three. On the contrary of what it is commonly assumed, the amplitudes and the resonance frequencies of these narrow peaks are not stable over time in $\mathrm{C} 3$. We determined the maximum of the amplitude of each peak with the corresponding central frequency for each day during $2.5 \mathrm{yr}$. Except for the station with three peaks, which finally appears stable within the uncertainties, the principal peak exhibits a seasonal variation, with a maximum in winter and a minimum in summer, the observations being more dispersed during winter. The second peak, when it exists, varies in the same way except at one station where it varies oppositely. These variations are clearly correlated with the loading and unloading cycle of the underlying aquifers as shown by the comparison with water level and yield measurements from wells located close to the stations. Moreover, they are also correlated with the vertical surface displacements observed at continuously recording GPS stations. The dispersion of the observed maximum amplitude in winter is probably related to the rainfall and the soil moisture modifying the $S$-wave velocity as revealed by other studies. From this study, we would like to emphasize that the use the HVSR method to constrain the $S$-wave velocity and the thickness of the sediment layer over the bedrock in the basin, has to be done with caution. Upon further confirmation of its robustness, the HVSR methodology presented here could be a good and easy-to-use tool for a qualitative survey of the aquifer backdrop and its seasonal behaviour, and of the soil moisture conditions.
\end{abstract}

Key words: Hydrology; Transient deformation; Europe; Time-series analysis; Site effects.

\section{INTRODUCTION}

The horizontal-to-vertical spectral ratio (HVSR) of seismic records is a common method to characterize the geological properties of the subsurface of the Earth. The intensive use of the Nakamura's method (Nakamura 1989, 2019) as stated by an abundant literature is due to its low-cost and fast deployment in the field, the easier and routine processing of the seismological data, as well as the agreement obtained between the HVSR results and other geophysical techniques and geological observations (Benjumea et al. 2011; Fehr et al. 2019). For decades (see Mucciarelli \& Gallipoli 2001; Molnar et al. 2018 for reviews), the HVSR method is used for site effect evaluations (Bonilla et al. 1997; Bonnefoy-Claudet et al. 2006; Guéguen et al. 2007; Moisidi et al. 2015; Molnar et al. 2018; Napolitano et al. 2018; Yassminh et al. 2019) and microzonation of large areas (Panzera et al. 2019) principally for seismic risk assessment and building damage predictions (Giannaraki et al. 2019). The other important application concerns the subsoil mapping in estimating the thickness and elastic properties of the shallow sediment (Chavez-Garcia \& Faccioli 2000; Harutoonian et al. 2013; Mulargia \& Castellaro 2016), and in constraining the basin structure (Hinzen et al. 2004; Oliveto et al. 2004; Borges et al. 2016; Mulargia \& Castellaro 2016; Bignardi 2017; Tarabusi \& Caputo 2017; Cipta et al. 2018; Molnar et al. 2018; Fehr et al. 
2019; Yassminh et al. 2019). Gas reservoirs and geothermal fields are also investigated by HVSR techniques characterizing the impact of fluids on the attenuation/dispersion of the seismic waves (Sarout et al. 2019).

The HVSR method starts with a Fourier transform of the three components of seismological records. The HVSR curve is the spectral ratio of the horizontal to the vertical component as defined by Nakamura (1989) in order to characterize the local site effects. What controls the shape of the HVSR curves is still in debate (Mucciarelli \& Gallipoli 2001), but it is generally admitted that it is controlled by the $S$-wave resonance in the sediments (Nakamura 1989) and/or by the polarization of the fundamental Rayleigh-Love waves (Lachet \& Bard 1994; Bard 1998) and the local wavefield composition (Bonnefoy-Claudet et al. 2008; Albarello \& Lunedei 2020), questioning about its applicability to precisely evaluate site amplifications (Bard 1998; Mucciarelli 1998; Bonnefoy-Claudet et al. 2006; Haghshenas et al. 2008). International recommendations were enacted for seismic site characterization about the experimental acquisition and the data analysis (SESAME Project 2004). Most studies based on HVSR techniques, process microtremors recordings on time windows at around 15-60 min. Earthquake signals are also considered, in order to compare their HVSR curves with those of the microtremors or seismic noise (Laurendeau et al. 2017; Yassminh et al. 2019), or to compare site conditions at various places with respect to a reference site characterizing, for example, topography or sediment-filled valley effects (Chávez-García et al. 1996; Malagnini et al. 1996; Souriau et al. 2011). The common interpretation of the HVSR curves assumes a simple model of the subsoil as a sedimentary layer with low shear wave velocity Vss overlying the bedrock with a faster shear wave velocity $V s b$. The evidenced peak and its corresponding central frequency, also called the resonance frequency $\left(f_{0}\right)$, are correlated with $V_{S S}$, that is the elastic properties, and the thickness of the superficial layer. If a seismological station is on bedrock, the HVSR curve is ideally flat with amplitude of 1 . Both peak and resonance frequency, when they exist, are related to the impedance contrast between the sediment layer and the bedrock. In some cases, HVSR curves have two or more peaks which can correspond, for frequencies higher than $f_{0}$, to higher harmonic modes of the first peak, linked to multiple reflection of $S$ waves in the sediment layer (Bonnefoy-Claudet et al. 2006), or, mainly for the second peak, to the existence of another strong impedance contrast in the sedimentary cover (Cornou et al. 2003; Mucciarelli 2011; Harutoonian et al. 2013; Moisidi et al. 2015; Lontsi et al. 2019). Due to local geometry and 3-D structural complexities, the HVSR results are often combined with other experimental observations such as borehole, geological and geophysical data (Moisidi et al. 2015; Fehr et al. 2019). As generally admitted, the 3-D complexities may explain why the HVSR method failed in predicting seismic strong ground motion, or in estimating at least its lower bound (Cornou \& Bard 2003; Bindi et al. 2009). For that, new models are proposed in order to take into account the multilayered subsoil rather than a simple 1-D model of a soft layer over a half space (Cornou \& Bard 2003).

A remarkable aspect of the HVSR curve, generally observed, is its stability over time (Mucciarelli \& Gallipoli 2001; Moisidi et al. 2015; Molnar et al. 2018). Nevertheless, recently Malagnini et al. (2019) studying the variations of the attenuation over several years from either side of the San Andreas Fault in Parkfield, observed cyclic variations of the amplitude of the HVSR curve at specific frequencies. They evidenced seasonal, semi-annual and annual periodicities, and they related it to hydrological loads and polar tides. Being interested on the variations of the seismic attenuation due to the 2004 Parkfield earthquake, they interpreted them as a consequence of the variations of the crack density in the crust, that is of the changes of the normal stresses. Here, we will focus on the seasonal variations of the amplitude of the peaks observed on HVSR curves to highlight the predominant role of the water content in the subsurface layer. In 2015, we installed temporary seismological stations in Western Greece, in Aitoloakarnania (Fig. 1), for surveying the seismic activity of the active faults located between the Gulf of Corinth and the Ionian Sea (Pérouse et al. 2017). Applying the HVSR method to our data, we found that at some stations the amplitude and the fundamental frequency $f_{0}$ vary, while other sites are stable over time. First, we describe the seismological network and the data used in this study, and the implemented methodology to process the HVSR curves. Secondly, we show that both amplitude and resonance frequency $f_{0}$ of the peaks for four stations and during $2 \mathrm{yr}$, fluctuate periodically. We show that these fluctuations are correlated with hydrological loads in the sedimentary layers by comparison with hydrological and GPS data.

\section{DATA AND METHOD}

From autumn 2015, we installed 16 temporary seismological stations in western Greece for seismotectonic purposes. This network covers the Aitoloakarnania region from the north coast of the Gulf of Patras to the city of Arta to the north, in order to monitor the seismic activity of the Katouna-Stamna fault system and the Trichonis Lake graben, forming the eastern boundary of the Islands Akarnanian Block (Vassilakis et al. 2011; Pérouse et al. 2017; Tranos et al. 2020). We will consider here 10 of the 16 stations (Fig. 1), that are those having the longest recordings without major interruption until the end of 2018, and free of component malfunctions or change of the sensor (hardware or configuration) during the observing period. All the stations are three-component recording continuously with a sample rate at $100 \mathrm{~Hz}$. The sensors are short period seismometers of different types: $2 \mathrm{~Hz}$ Sercel L22E (SS04), 5s Lennartz LE-3D (SS08, SS13, SS20, SS22, SS24) and $1 \mathrm{~Hz}$ Geosig VE-53 sensor (SS09, SS17, SS19, SS21), the data loggers being DataCube (SS04, SS08, SS20, SS24) and Earthdata (SS09, SS13, SS17, SS19, SS21, SS22). For safety reasons, the stations were installed in schools (old or still active) or in public buildings. Some sensors are inside the building laid on a cemented floor (SS04, SS08, SS13, SS20, SS22, SS24) that may affect the quality of the HVSR's curves (SESAME Project 2004; Castellaro \& Mulargia 2009), the others are buried outside close to the building (SS09, SS17, SS19, SS21).

The data were processed with the Geopsy software (www.geop sy.org; Wathelet et al. 2020). We applied a second order band pass Butterworth filter [0.05-10 Hz] to the three components. For $1 \mathrm{~d}$, we calculate a mean HVSR curve between 0 and $10 \mathrm{~Hz}$ undistinguishing anthropogenic noise, ambient seismic noise or microtremors, and earthquake signals. In fact, several studies strongly suggest that the HVSR curves are very similar considering microtremors or seismic event records (Nakamura 2019) both for site effect characterization (Laurendeau et al. 2017; Yassminh et al. 2019) and for basin structure (Borges et al. 2016). In order to verify that, we calculated HVSR curves separately for seismic ambient noise and for earthquake signals at different days as shown in Fig. 2(top panel) for station SS19. Even if the curves are noisier at low frequencies for the earthquake signals (dashed lines) probably due to the corner frequency of the sensor at $1 \mathrm{~Hz}$, the two amplification peaks are recovered for both types of signal at the same frequencies, but with mean amplitude slightly lower for the earthquake signals, the difference being at 


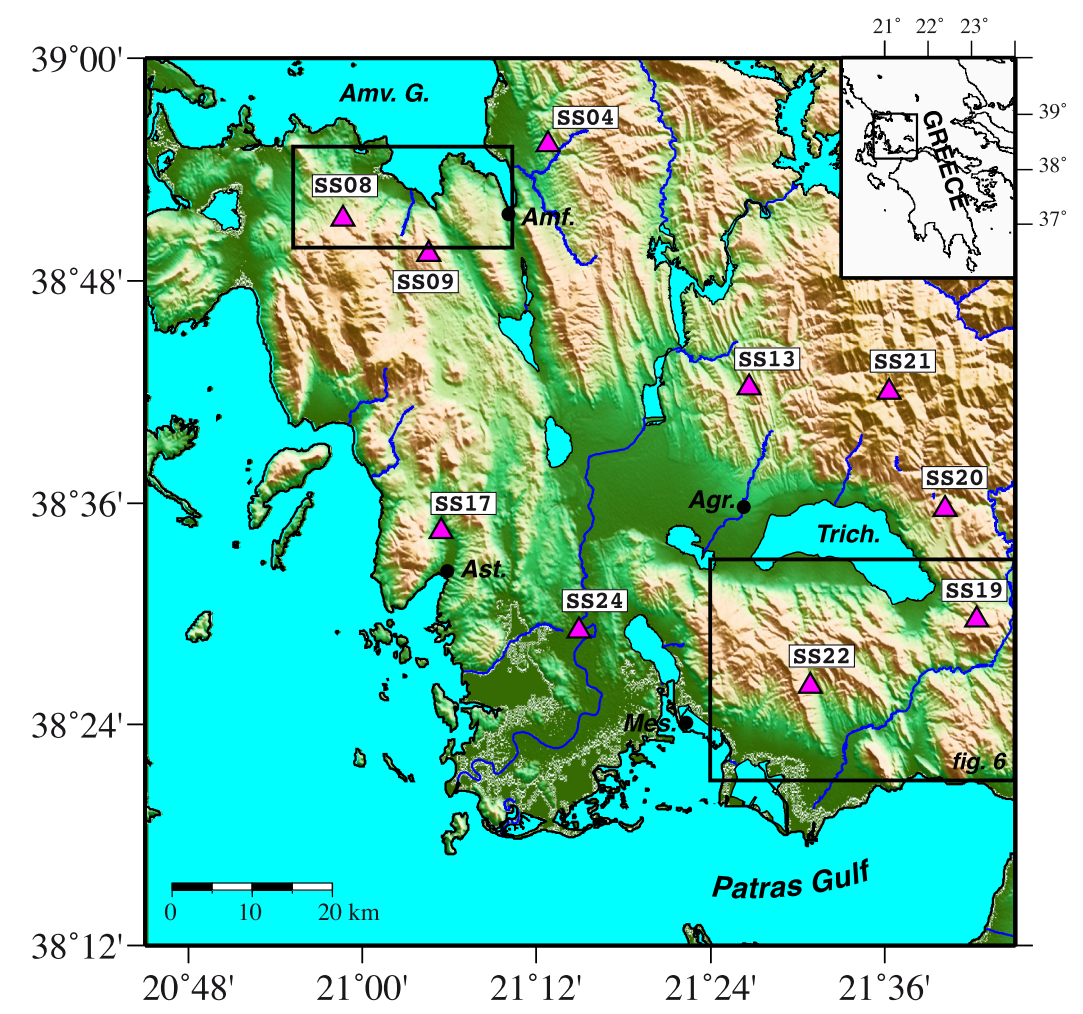

Figure 1. Location map of the study seismological network. Inset at the top right: location map of the study area. Extend of Figs 5 (a) and 6 are shown. Agr.: Agrinio; Amf.: Amfilochia; Amv. G.: Gulf of Amvrakikos; Ast.: Astakos; Mes.: Mesologhi; Trich.: Lake of Trichonis.

maximum 15 per cent. Nevertheless, looking at the details on this specific case, a few individual HVSR curves for earthquake signals have amplitudes greater than those for noisy signals. Also, it is important to note that in the study area, there is no day without local or regional earthquakes recorded at the stations. Thus, our choice not to distinguish the different kinds of signals in the records for the HVSR processing does not affect the fundamental frequencies of the peaks, but may affect their mean amplitudes by around 10 per cent. To evaluate the site conditions at each seismological station, we determine a mean daily HVSR curve. For that, we calculate the HVSR on a 1-hr time window, $1 \mathrm{hr}$ out of two over the entire day without overlapping of the data, the mean daily HVSR being the average of the 12-hr calculated HVSR's. As shown in Fig. 2(bottom panel), there is no difference between the 24-hr estimation (dashed line) and the 12-hr estimation (full line), which is preferred here for its reduced time processing.

\section{RESULTS}

We calculated the daily HVSR curves following the procedure described before at days chosen randomly and at each station. In Fig. 3, we show the daily HVSR curves from 0.5 to $10 \mathrm{~Hz}$ with their 80 per cent confidence interval by grey curves, obtained for the 10 stations of the temporary network. The colour of the curve corresponds to the number of days since 1 October 2015, the last day being 31 December 2018 (day number 1186). The HVSR curves are very different from one station to another and their standard deviations are overall stable over time. One first remarkable point concerns the blue curves, which exhibit a change in shape at all sites. They correspond to the days following the $M_{\mathrm{w}} 6.8$ Zakynthos earthquake of 25 October 2018 (day number 1119), and they will be discussed later. Nevertheless, it is worthy to note that at SS17 the curves with
$\mathrm{H} / \mathrm{V}$ amplitude smaller than 1 , are due to a malfunction of the sensor (failover or electronic failure), with a strong amplification of the vertical component, and at SS21, the station has been moved $280 \mathrm{~m}$ for safety reasons in November 2018 implying a different subsurface environment. We classify the stations according to their HVSR curve features into three categories: (i) curves without peak (C1) at stations SS04, SS09 and SS21; (ii) curves with a peak covering a wide range of frequencies (C2) at SS17, SS20 and SS24 and (iii) curves with one or more narrow peaks (C3) at SS08, SS13, SS19 and SS22.

In category $\mathrm{C} 1$, station SS21 is currently installed in the mountains, at $1000 \mathrm{~m}$ of altitude, on Jurassic bedrock without sedimentary layers. The HVSR curves at the initial installation site are flat coherently with its geological environment. At the second site (blue curves), the differences in frequencies greater than $2 \mathrm{~Hz}$ can be due to the change of the installation site $280 \mathrm{~m}$ apart with a different subsoil with the possible presence of a different weathering sediment layer overlying the hard rock as typically found in rocky mountain environment (Sivaram et al. 2012; Di Naccio et al. 2017), or to the effect of the Zakynthos seismic sequence. Unfortunately, we don't have enough data to choose one of these hypotheses. SS04 is installed on Oligocene flysch of the Ionian Zone and the site of SS09 corresponds geologically to the Tryfos formation composed by Triassic conglomerates. The HVSR curves at SS04 and SS09 have large convex and concave shapes, respectively. These features are stable over the study time period, but station SS09 is noisier, most probably because the sensor is buried in a surficial layer of gravels of 2-3 $\mathrm{m}$ thick.

In category $\mathrm{C} 2$, the HVSR curves evidence a peak over a large frequency range from 2 to $10 \mathrm{~Hz}$ with a maximum amplitude at 3 at $5 \mathrm{~Hz}$ at $\mathrm{SS} 17$, from 1.5 to $4 \mathrm{~Hz}$ with a maximum amplitude at 2.7 at SS20, and from 1 to $4.5 \mathrm{~Hz}$ with a maximum amplitude comprised 

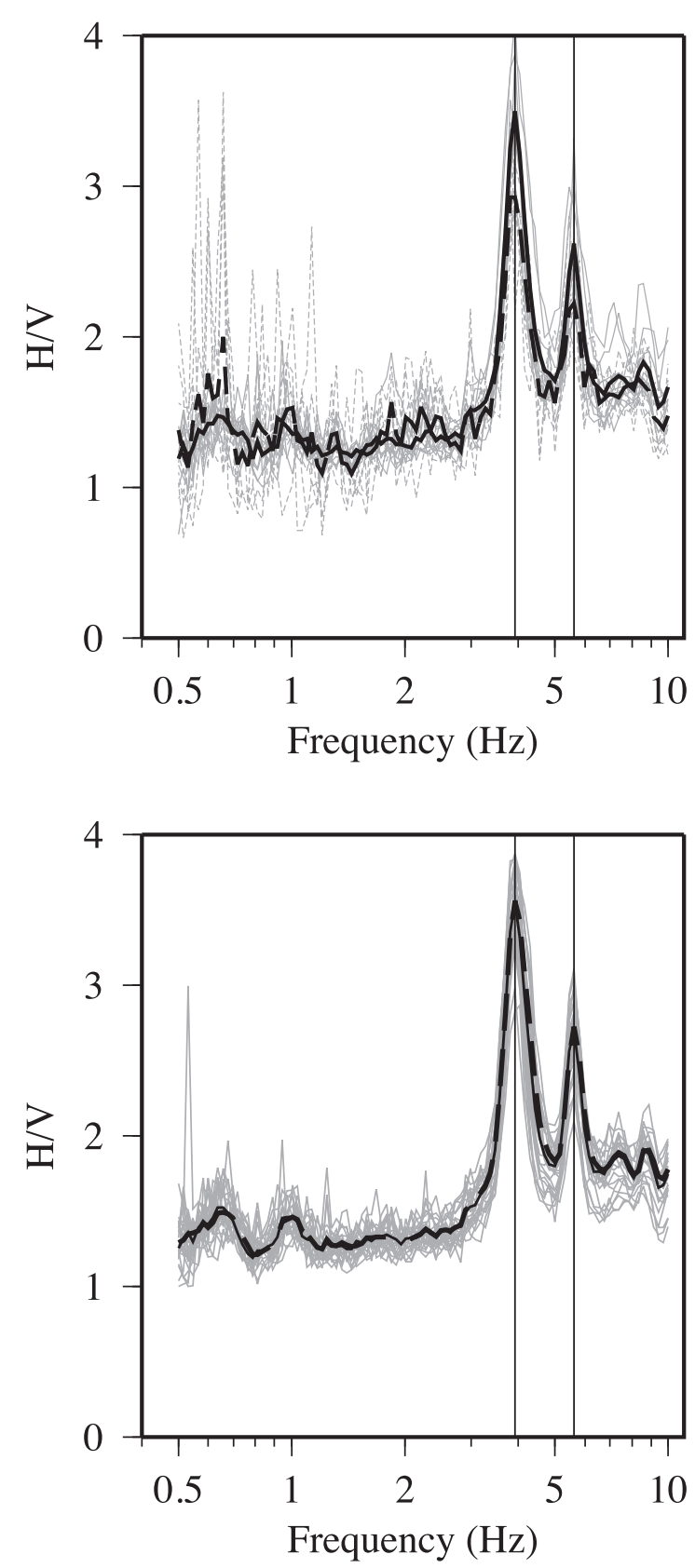

Figure 2. Example of HVSR curves at SS19 on 03/17/2018. Top panel: solid lines correspond to the ambient noise with the average (bold), and the dashed lines to the seismic signals with the average (bold). Bottom panel: each grey curve corresponds to $1-\mathrm{hr}$ window processing, the bold continuous line to the 12 -hr average, and the bold dashed line to the 24-hr average. The vertical lines point peak frequencies at 3.9 and $5.6 \mathrm{~Hz}$, respectively.

between 4 and 5.2 at SS24. These HVSR features are very stable over the observed time period with more (SS24) or less (SS17) noise. At station SS17, the site amplification could be related to the presence of fluvial alluvium above an Eocene limestone. The geological environment at SS20 and SS21 is composed of red shales of Jurassic and upper Jurassic of the Pindos Unit. Nevertheless, the HVSR curves are very different between these two sites probably due to the different local geological environment. While SS21 is installed on rock, SS20 is installed in a public building located on alluvium of a small river. This alluvium a few meters thick may explain the presence of the peak with a small amplitude in the HVSR curve. Station SS24 is located on a small hill of Triassic breccias surrounded by alluvium. The site amplification, stable in time, can be related to the small topography and lateral geological complexities.

In the third category $\mathrm{C} 3$, the HVSR curves are characterized by one (SS22), two (SS08 and SS19) or three (SS13) narrow peaks (Fig. 3) meeting the criteria of 'clarity' (SESAME Project 2004). The geological environment at SS08 is similar to that of SS09, and it is constituted by folded flysch from the Gavrovo-Tripolis Zone at sites SS13 and SS22. SS19 is situated over Cretaceous limestone from the Pindos Zone of at least $500 \mathrm{~m}$ thick. At station SS22, the peak has a fundamental frequency $f_{0}$ at around $5.8 \mathrm{~Hz}$. The peak at 2$3 \mathrm{~Hz}$ appears after the Zakynthos seismic sequence. At station SS08, the central frequencies of the two peaks P1 and P2 are at 5.6 and $7.6 \mathrm{~Hz}$, respectively, and at station SS19 at 3.6 and $5 \mathrm{~Hz}$, respectively. Regarding the site SS13, we can distinguish three permanent peaks P1-P3 (Fig. 3) with central frequencies at 2.8, 3.4 and $8.3 \mathrm{~Hz}$, respectively. The two peaks visible at frequencies smaller than $2 \mathrm{~Hz}$ appear in very rare cases and they are not considered as amplification peaks. Because the frequency of P3 is three times the frequency of P1, P3 may correspond to the second mode of oscillation (Haskell 1960) that may indicate that the seismic records are constituted by both body and surface waves (Bonnefoy-Claudet et al. 2008). We choose this possibility, even if the $\mathrm{P} 3$ peak could be also related to the presence of a very near-surface layer. As it can be seen in Fig. 3, the maximum of the peak amplitudes varies through time by a factor from 1.5 (SS13 and SS22) to 2 (SS08 and SS19). In the same way, the peak frequencies also vary at maximum by 10 per cent, which is commonly assumed as a marginal variation (SESAME Project 2004; Lontsi et al. 2019).

In order to more accurately characterize the variations in amplitude and fundamental frequency in time, we calculated the daily HVSR over the operating time of the seismic stations for the four sites of the category C3. In Fig. 4, we report the maximum amplitudes of the peaks and the corresponding resonance frequencies, with the observed rainfall recorded at close by meteorological stations (http://meteosearch.meteo.gr/), versus time. We filtered the amplitudes with a median sliding box of $60 \mathrm{~d}$ width. Thus, Fig. 4 shows a more or less well-expressed seasonal variation both in the amplitudes of the peaks and in their central frequencies. Another common feature on all the stations is that both peak amplitudes and resonance frequencies are more scattered during winter and spring, that is the wettest period of the year, than during summer, that is the driest period. At SS08, the first peak P1 amplitude has a minimum covering 3-4 months in the summer, and a maximum with a 6-month plateau (from October to April). On the contrary, the peak P2 amplitude has its maximum during summer, and the minimum in winter, with less dispersion compared to P1. At the same time, but for both peaks $\mathrm{P} 1$ and $\mathrm{P} 2$, the fundamental frequencies are minimum in summer and maximum in winter, with variations of \pm 7 and \pm 9 per cent, respectively. At SS19, there is also a well-expressed seasonal variation of the peak amplitudes and frequencies, but here both peaks $\mathrm{P} 1$ and $\mathrm{P} 2$ vary in the same way: maximum in winter and minimum in summer. The H/V amplitude varies from 2 to 3 and from 1.5 to 2.3 for $\mathrm{P} 1$ and $\mathrm{P} 2$, respectively, and the central frequency varies at \pm 7 per cent and at \pm 11 per cent for $\mathrm{P} 1$ and $\mathrm{P} 2$, respectively. The values smaller than $3 \mathrm{~Hz}$ for P1 (dashed ellipse with Z in Fig. 4) are linked to the 2018 Zakynthos seismic crisis. On the contrary to what seems in Fig. 3, the variation of the peak amplitudes at station SS22 is at around 30 per cent. The central frequency at SS22 has also a seasonal variation with a minimum during summer at around 

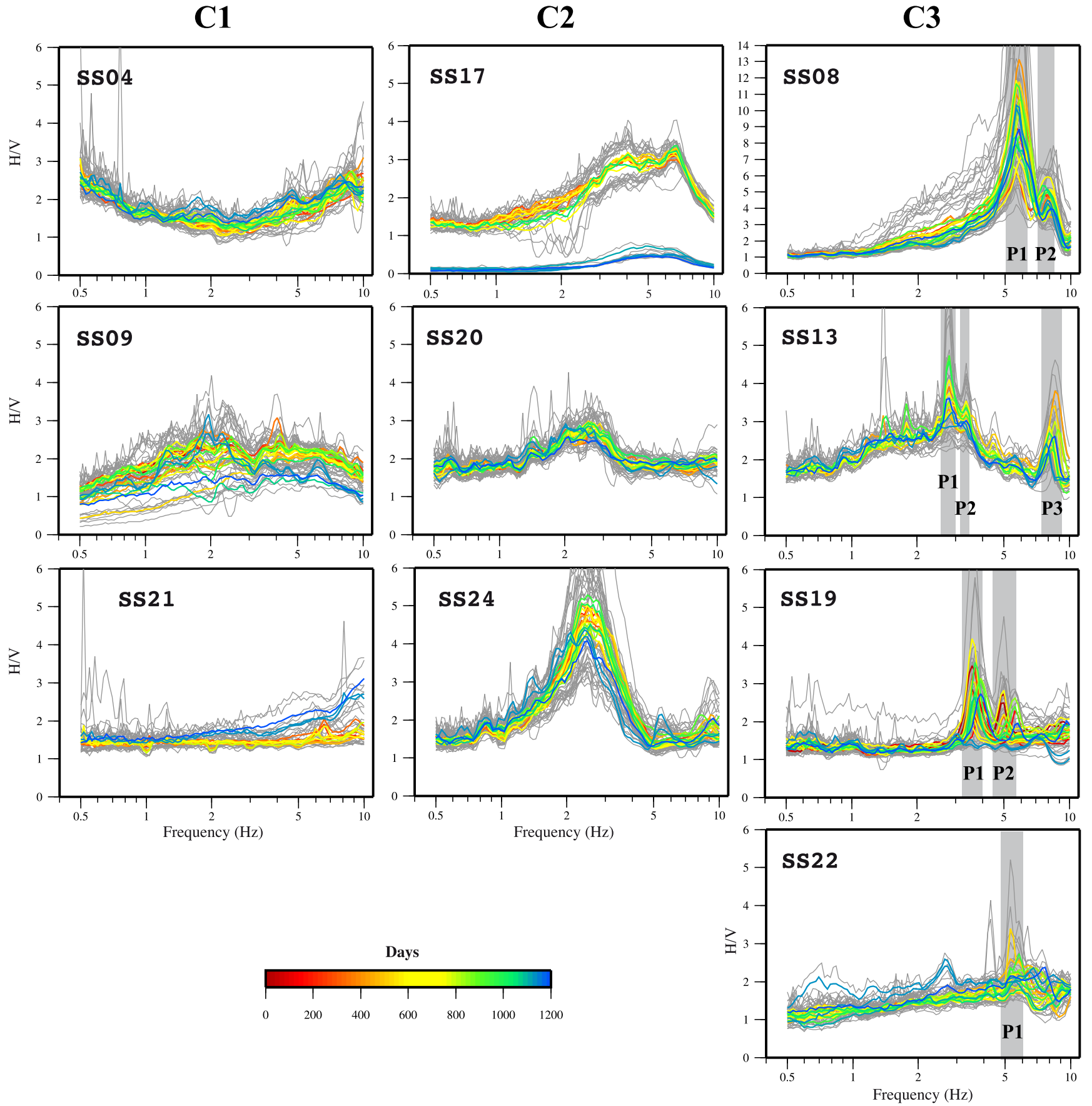

Figure 3. Daily HVSR curves with their 80 per cent confidence standard deviation (grey curves). Columns $\mathrm{C} 1, \mathrm{C} 2$ and $\mathrm{C} 3$ correspond to categories $\mathrm{C} 1$, $\mathrm{C} 2$ and C3, respectively described in the text. The colour scale corresponds to the number of days after 2015/10/01. The grey zones correspond to the amplification peaks whose amplitude varies with time.

$5.3 \mathrm{~Hz}$ and a maximum during winter at around 5.8-6.0 Hz. On the contrary, at station SS13 the resonance frequency is very stable at 2.8 and $3.4 \mathrm{~Hz}$ for $\mathrm{P} 1$ and $\mathrm{P} 2$, respectively, with a few marginal values. At the same time, the amplitudes of both peaks at SS13 have no clear seasonal variations, and $\mathrm{P} 1$ exhibits a maximum in April 2018, not observed in April 2017, and the HVSR amplitude does not vary more than 12 per cent for both peaks. Finally, contrary to what Fig. 3 shows, the variations of the peak amplitudes at station SS13 are small and have to be considered as stable in time.

\section{CORRELATION WITH GROUNDWATER CYCLE}

The observations previously described clearly evidence a seasonal variation of the amplitudes and the central frequencies of the peaks, for four seismological stations among the 10 of the network. The amplitudes and the frequencies for the first peak are maximum in winter and minimum in summer, corresponding also to the wet and dry periods of the year, respectively, as shown by the rainfall measurements (Fig. 4). At site SS19, the amplitudes and frequencies 

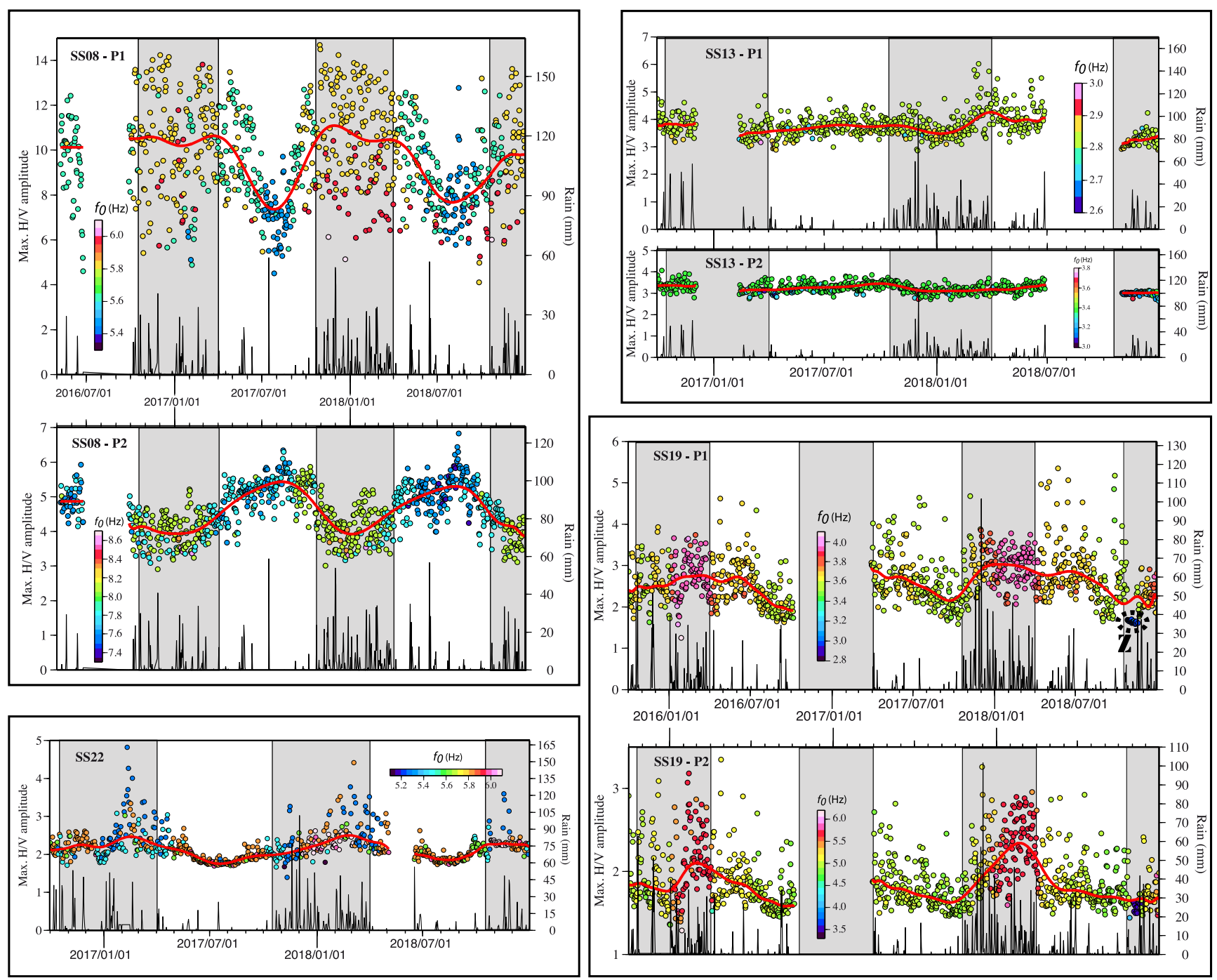

Figure 4. Plot of HVSR peak amplitudes and of corresponding resonance frequencies f0 (colour scales) variations versus time. Rainfalls are from the closest meteorological stations (http://meteosearch.meteo.gr/). The red curves are done with a median sliding box of $60 \mathrm{~d}$ width. The grey areas correspond to the wet periods in western Greece from approximately half of October to end of March. The black dashed ellipse with the letter Z in the P1 peaks at SS19 outlines the Zakynthos earthquake effect (see text for details). Station name and frequency peak are done at the top left corner of each panel.

of the second peak P2 follow the same variation as P1, but at SS08 the amplitude of P2 is minimum in winter and maximum in summer, while the central frequency is varying similarly to other sites. Such seasonal variation phased with the precipitations and repeating each year, leads to correlate it with the seasonal variation of the groundwater content, and specifically with the charge and discharge of the aquifers. Even if that is still debated, the HVSR curves are controlled by or, at least, are sensitive to the $S$ waves and surface waves (Nakamura 1989; Lachet \& Bard 1994; Bard 1998). As it is well known, $S$ waves and surface waves, as $P$ waves to a lesser extent, are sensitive to the presence of water, which modifies their velocity, even if its presence is restricted to the subsurface (Nur \& Simmons 1969; Husen \& Kissling 2001; Rigo et al. 2008).

In order to test this hypothesis, we attempt to compare the temporal variations of the HVSR curves with groundwater observations. The site SS08 is located close to a borehole (PN in Fig. 5a), where the level of the aquifer is measured each day except during the 10-d Christmas period. Also, at $15 \mathrm{~km}$ to the east, there is a continuous recording GPS station named AMFI installed in 2015 (Fig. 5a). The loading and unloading of aquifers may induce local and small vertical displacements of which amplitudes depend on the elasticity of the subsurface layer and on the depth of the aquifer, and which can be monitored by continuous GPS measurements as shown by Larochelle et al. (2018) and Burnol et al. (2019). Even if AMFI is not located above the same water body than that of SS08 according to HSGME (Hellenic Survey of Geology and Mineral Exploration, http://www.igme.gr), the seasonal cycle of load and unload should be approximately the same. In Fig. 5(b), we plot the filtered variations of HVSR amplitudes of P1 (continuous red line) and P2 (dashed red line), the water level at PN (blue dots) also filtered with a median sliding box of 60-d width (blue curve) and the vertical GPS coordinates (triangles) and its filtered curve (same filter, black curve). As observed, the vertical GPS coordinates vary from $1 \mathrm{~d}$ to another by $10-15 \mathrm{~mm}$, but filtering the series allows reducing these uncertainties to $3-5 \mathrm{~mm}$. There is a correlation between the three observations. Indeed, in winter, the maximum amplitude of the P1 peak [which also corresponds to the maximum value of its central frequency (Fig. 4)], corresponds to a high level of the aquifer, and at a minimum of the altitude of the GPS station due to the elastic response of the ground to the weight of the aquifer water (Larochelle 

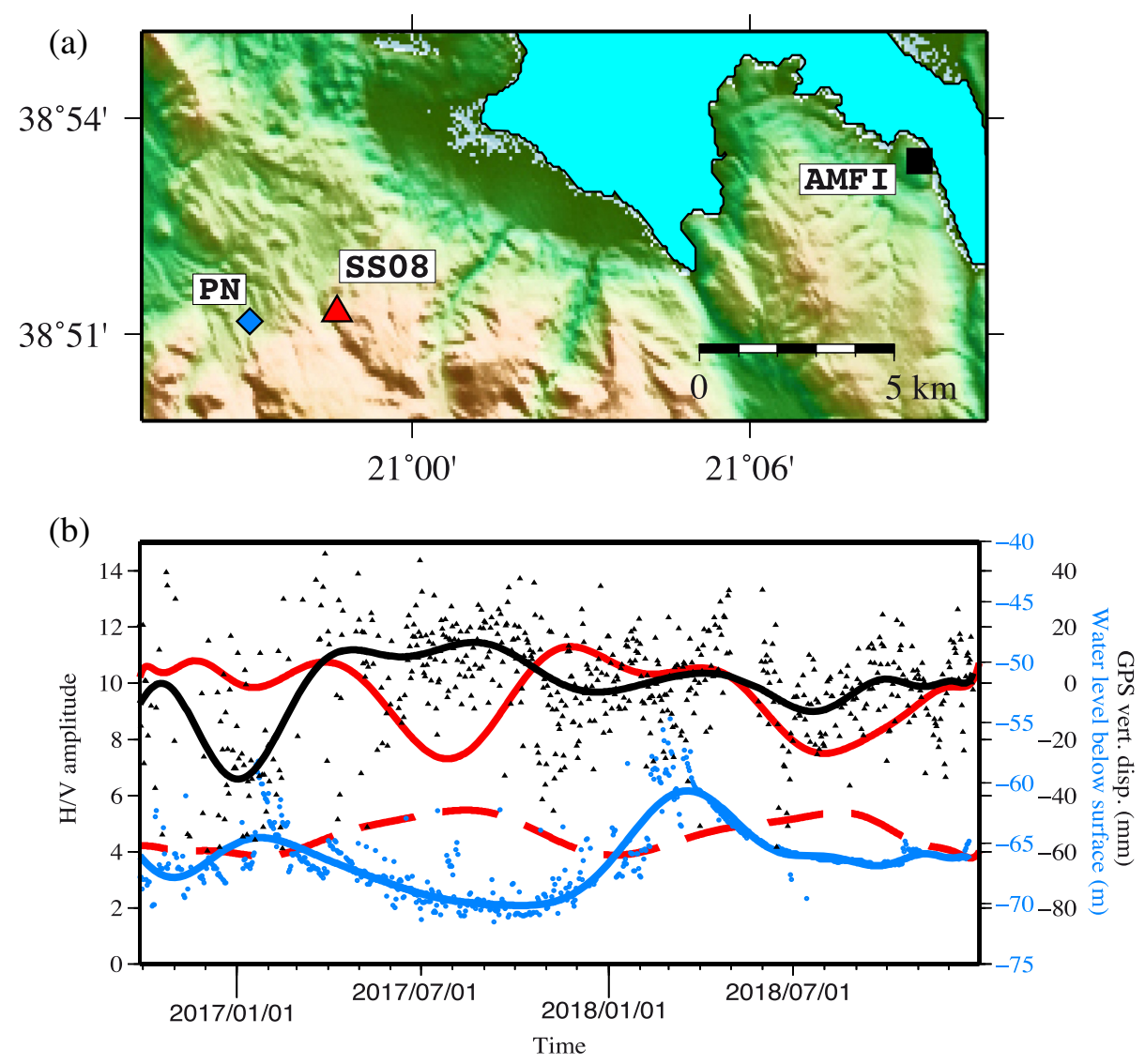

(c)

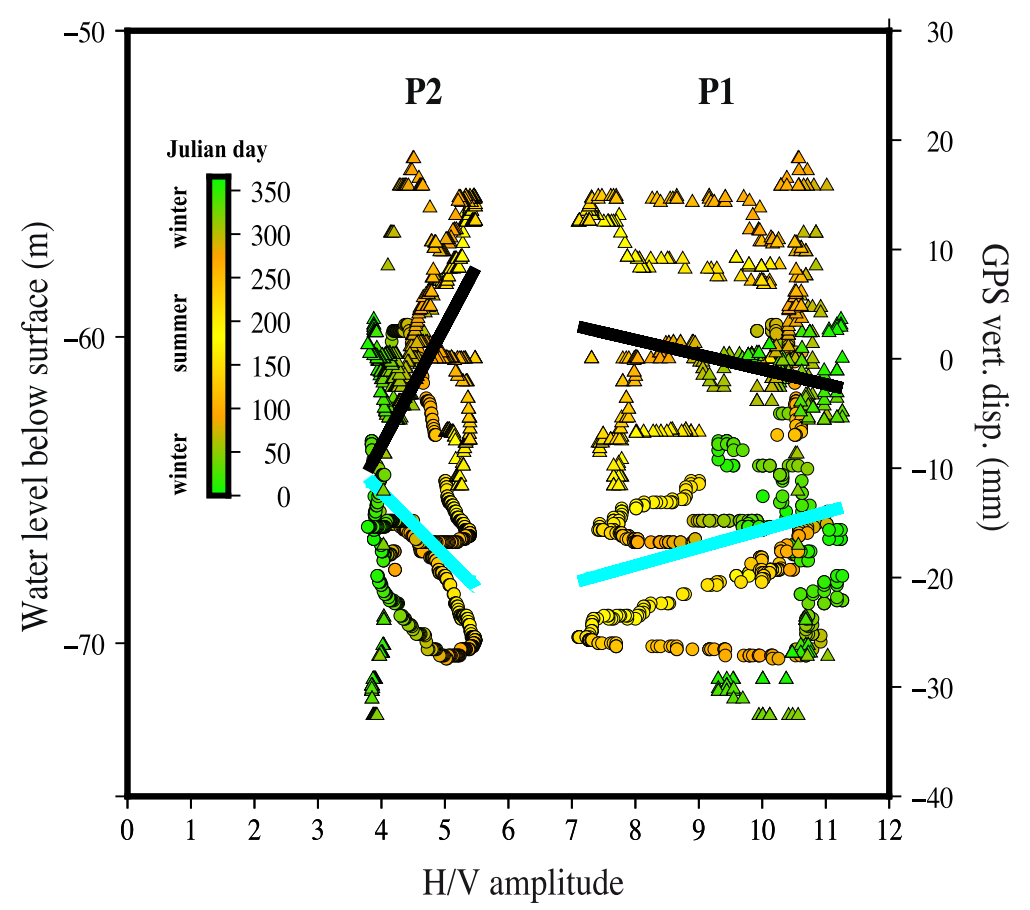

Figure 5. (a) Location map of the SS08 station, the water well PN and the continuous recording GPS station AMFI. (b) Time variations filtered with a median sliding box of $60 \mathrm{~d}$ width of the HVSR peak amplitudes (red) for P1 (continuous) and P2 (dashed), of the GPS vertical positions at AMFI (black triangles and curve), and of the water level below the surface at PN (blue circles and curve). (c) Fits between H/V amplitude, water level (circles), and GPS vertical displacements (triangles) for the peaks P1 and P2 at station SS08. Cyan lines represent the linear fit of H/V amplitude and water level, black lines represent the linear fit of $\mathrm{H} / \mathrm{V}$ amplitude and GPS vertical positions. The colour scale indicates the Julian day. 


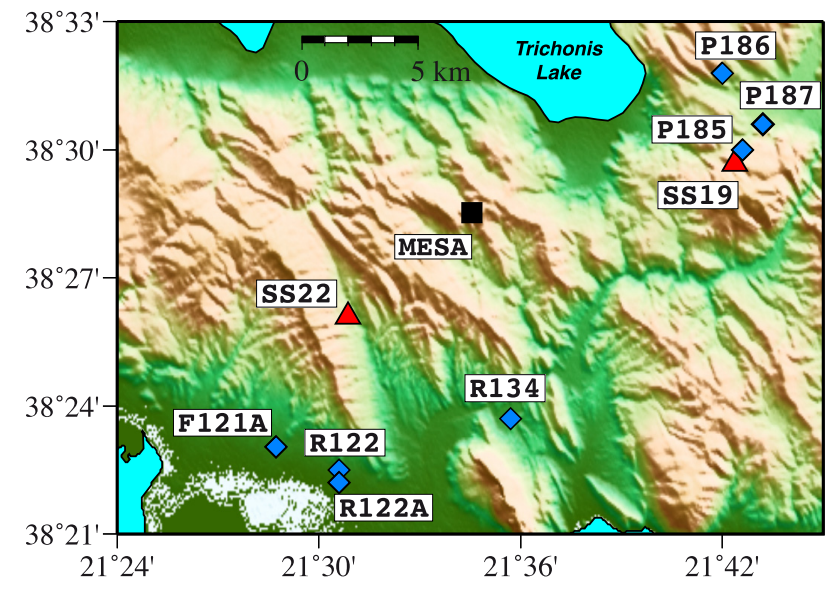

Figure 6. Location map of SS22 and SS19 stations, of the closest water wells, and of the continuous recording GPS station MESA.

et al. 2018). Conversely, in summer, the amplitude of $\mathrm{P} 1$, its resonance frequency, and the level of the aquifer are minimum while the altitude of the GPS point is at a maximum. We can also note that the amplitudes of the second peak $\mathrm{P} 2$ are correlated with the vertical AMFI coordinates, the central frequency varying oppositely, indicating that the second peak is also linked to the presence of the water table and its loading cycle but in a different way than the first peak. These correlations are also visible in Fig. 5(c) where the peak amplitudes are reported versus the water levels and the GPS vertical positions, the colour scale distinguishing winter and summer periods. Although the fits are not good, they bring out the tendency, that is for $\mathrm{P} 1$ a positive fit between the amplitudes and the water levels, and a negative fit between the amplitudes and the GPS positions as described before. And for $\mathrm{P} 2$, the fit is negative between the amplitudes and the water levels and positive between the amplitudes and the GPS positions. As expected, the winter values are at the maximum amplitudes for P1 and at the minimum amplitudes for $\mathrm{P} 2$. The low fits are due to the intermediate values during spring and autumn periods.

Regarding the sites SS19 and SS22, we have plotted in Fig. 6 the locations of the closest wells, with water level and/or water yield measurements archived by HSGME, and the continuous recording GPS station MESA. Unfortunately, the measurements at the wells are made only 5-15 d a year. Moreover, there are very few measurements during the operating period of our network. For that reason, we will consider several wells around the seismological site, and we will stack the observations, that is the observations are reported on $1 \mathrm{yr}$ in order to retrieve an annual and/or seasonal behaviour of the observed parameters. To compare them with each other, all the observations (wells, amplitude of the peaks and vertical GPS coordinates) are normalized to their corresponding maximum values. In that way, we seek to bring out a mean annual behaviour. In the stacked diagrams (Figs 7a and 8a), we reported the peak amplitude in red, the vertical GPS position in black and the wells measurements with blue symbols. Because of the scarce well measurements, the values can be very different from $1 \mathrm{yr}$ to another. Then, we draw in these diagrams by grey areas the envelopes including all the values, the mean variations being done by the dotted black line. For station SS19, the yield measurements of three wells (P185, P186 and P187) related to the same water table, and the vertical MESA coordinates are compared to the amplitude variations of P1 (continuous line) and P2 (dashed line) in Fig. 7(a). The wells were sampled from 2005 to 2008, but not at the same frequency. Even if the grey area including the well measurements is large-especially during winter between days 50 and 150 (March to May) - its general trend is coherent with a yield rate decreasing in summer between days 200 and 260, that is between half July and half September, and increasing in autumn after day 280 (beginning of October), which can correspond to the loading of the aquifer. This pattern is in agreement with the variation of the amplitude of $\mathrm{P} 1$, but the variation of the amplitude of P2 is less significant especially after the day 100. Even if the vertical GPS coordinates have no significant variation on the stacked diagram (Fig. 7a), it is clear looking over the observation period (Fig. 7b) that they are anti correlated with the P1 amplitudes, denoting a relationship with the loading cycle of a water table. At SS22 (Fig. 8), the borehole measurements cover the period from 2004 to 2018 but without data for the periods 20082012 and 2016-2017. They correspond to the water level at four wells located to the south of the seismological site (Fig. 6). On the stacked diagram (Fig. 8a), a possible correlation is visible between the variation of the water level and the amplitude of the peak between the day 150 and the end of the year, but the anticorrelation with GPS is not significant. However, two remarks must be made: the peak amplitude shows large values at the start of each year (February-March) with a greater dispersion (Fig 4). Consequently, the maximum of the peak amplitude is amplified between day 0 and day 150 . On the other hand, wells show water levels varying slightly all along the year as boreholes F121A (quasi null variation between days 0 and 200 with an aberrant value at day 330), and R122A. These two wells are more recent and were opened in 2013. The comparison with the vertical GPS coordinates at MESA also highlights an anticorrelation with the amplitude of the peak especially in 2017 but not obvious in 2018 (Fig. 8b). Even if, according to the HSGME data, MESA and SS19 are above the same groundwater body, both sites SS19 and SS22 seem to be compatible with the aquifer loading and unloading cycles, but need more precise investigations.

As mentioned before, it appears that there is an effect of the October 2018, M6.8 Zakynthos earthquake on amplitude and resonance frequency values of the peak and on the general form of the HVSR curves (Figs 3 and 4). This effect concerns the HVSR amplitudes, the appearance and disappearance of secondary peaks and the values of the central frequency of the permanent peaks. For example, the blue curves in Fig. 3 corresponding to the time after the Zakynthos earthquake occurrence evidence that (i) site SS09 has lower HVSR amplitudes; (ii) P1 and P2 peaks disappears at site SS19, as that is also visible on Fig. 4; (iii) The HVSR amplitudes are higher at station SS21 especially at frequencies greater than $2 \mathrm{~Hz}$ and (iv) at station SS24, several peaks appear between 1 and $2 \mathrm{~Hz}$, and the width of the large peak is reduced by at least $1 \mathrm{~Hz}$. We observe that these peculiar daily HVSR curves return to their previous shape as observed before the Zakynthos earthquake (Fig. 3) after two to more than six weeks depending on the stations. We plot in Fig. 9 the aftershock sequence following the Zakynthos M6.8 main shock with the mean magnitude per day, from the National Observatory of Athens (NOA) catalogue up to the end of 2018, and the days when the HVSR curves returned to their previous form for each station, the epicentral distances to the main shock, ranging from 130 to $180 \mathrm{~km}$, being also indicated. The station SS22 is indicated with a dashed line because its return time is after the 31 December 2018. As we can see, the return time to the previous form of the HVSR curves, that is the end of the apparent effect of the Zakynthos event, does not depend on the number of aftershocks, nor on the average magnitude, and nor on the epicentral distance. 
(a)

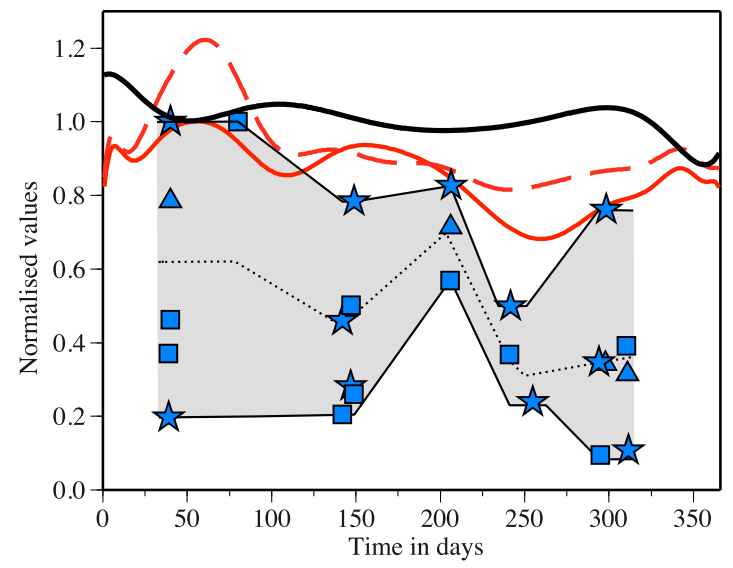

(b)

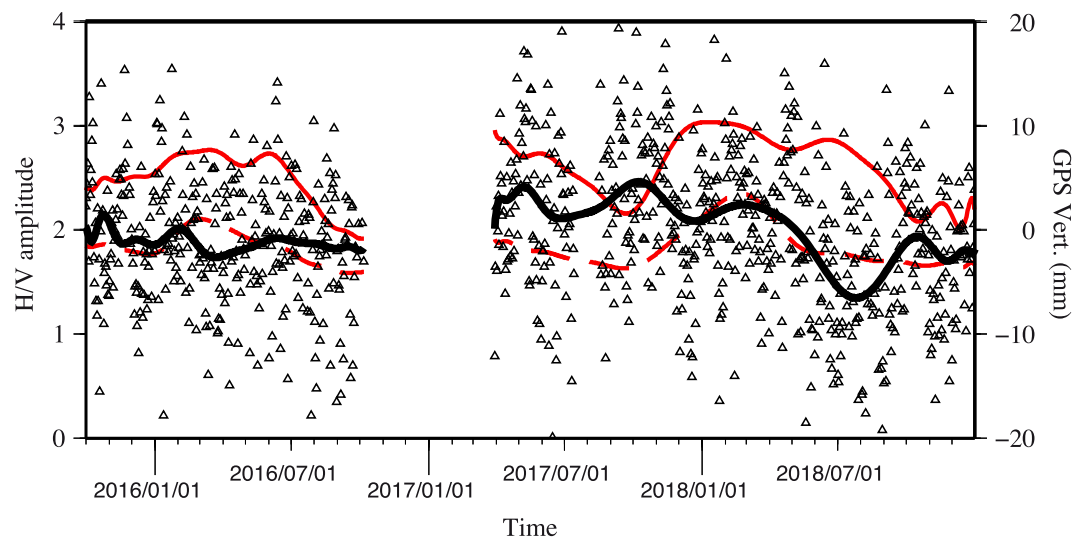

Figure 7. Temporal variations at station SS19. (a) Stacked time: red lines: HVSR amplification peak amplitudes for P1 (continuous) and P2 (dashed); thick black curve: GPS vertical coordinates observed at MESA, all filtered with a median sliding box of $30 \mathrm{~d}$ width. Normalized discharges at wells P185 (stars), P187 (triangles), and P186 (squares); grey area: discharge envelope (see text for details). (b) Red curves are the HVSR amplification peak amplitudes for P1 (continuous) and P2 (dashed) and in black is the GPS vertical coordinates at MESA (triangles), the applied filter for the curves is a median sliding box of $60 \mathrm{~d}$ width.

\section{DISCUSSION AND CONCLUSION}

Following the installation of a temporary seismological network in the north of the gulf of Patras, western Greece, we calculated the HVSR curves at each station in order to control the quality of the chosen sites. We determined a daily average curve from 12 hourly curves calculated every $2 \mathrm{hr}$ without distinguishing between ambient noise and seismic signal. Concerning the two sites (SS08 and SS09), which are active primary schools and SS20 which is an educational environmental centre, it is worthy to note that the working time in Greece is from 8 a.m. to 2 p.m., out of week-ends and vacancies. Moreover, during the major part of the time, students are in their classrooms generating no noise. Then, because of our procedure sampling $3 \mathrm{H} / \mathrm{V}$ curves during the working time over the 12 sampled, we consider that the activity in the schools do not significantly influence the mean $\mathrm{H} / \mathrm{V}$ daily curves at that sites.

There is also a possible effect of the building in which the seismic sensor is installed. According to various factors (the type of masonry, the form of the building, the number of floors, etc.), a building has is proper frequency. We estimated this frequency using the simple common formula linking $f_{0}$ to the number of floors, $f_{0}=10 /$ (number of floors) reported in Table 1 . As indicated, all the buildings have no floor except the one at site SS20 with 2 floors giving a proper frequency at $5 \mathrm{~Hz}$. In all cases, the proper frequencies of the buildings do not interfere with the central frequencies of the observed peaks.
The obtained HVSR curves are of three types: without site effect, with a broad peak, and with one or more narrow peaks. As it is commonly accepted, all of these curves are stable over time, except for the four stations SS08, SS13, SS19 and SS22 of the third group. We then showed, for these four cases, that the amplitude of the first peak - and of the second one when it exists - and the resonance frequency, vary seasonally. It is remarkable that both parameters are high and stable in winter and low and stable in summer. This variation is in phase with the loading and unloading cycle of the underlying aquifers. This aquifer cycle induces the elastic response of the soil to the weight of the water and a vertical surface displacement of tens of millimetres is detected by neighbouring continuously recording GPS stations, as already observed in other places in the world (Rigo et al. 2013; Clements \& Denolle 2018; Larochelle et al. 2018).

As known, site effects are linked to local geology and topography. In order to have good quality records and reduced site effects, we tried as much as possible to install the seismic stations on bedrock. We can consider that the site effects at SS04 and SS21, which are located on Oligocene flysch of the Ionian zone and Jurassic radiolarites of the Pindos zone, respectively, are those of stations on bedrock (Fig. 3). Only station SS17 has been installed on alluvium that most probably explains the large peak between 2 and $10 \mathrm{~Hz}$. Surprisingly, its amplitude is stable in time and it seems that this is the case, each time the peak is wide, as it is also visible for the stations SS20 and 
(a)

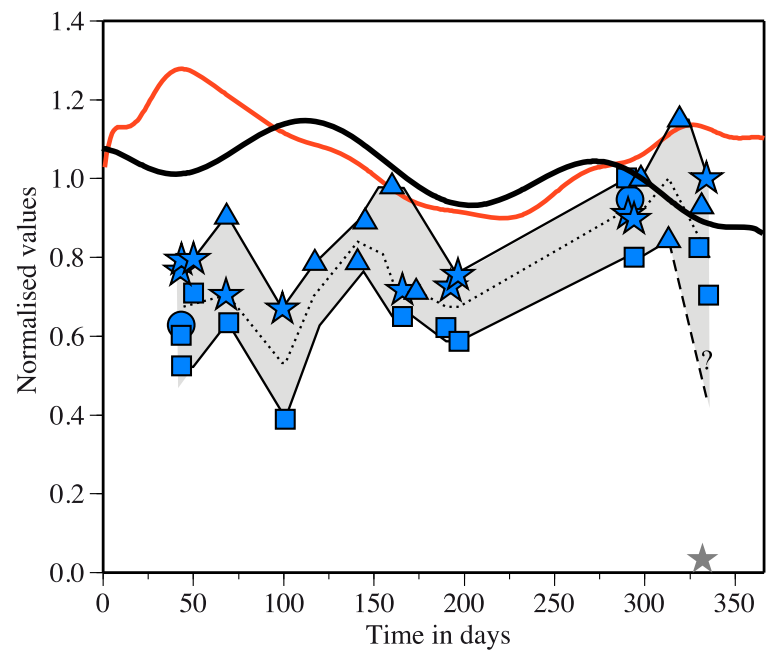

(b)

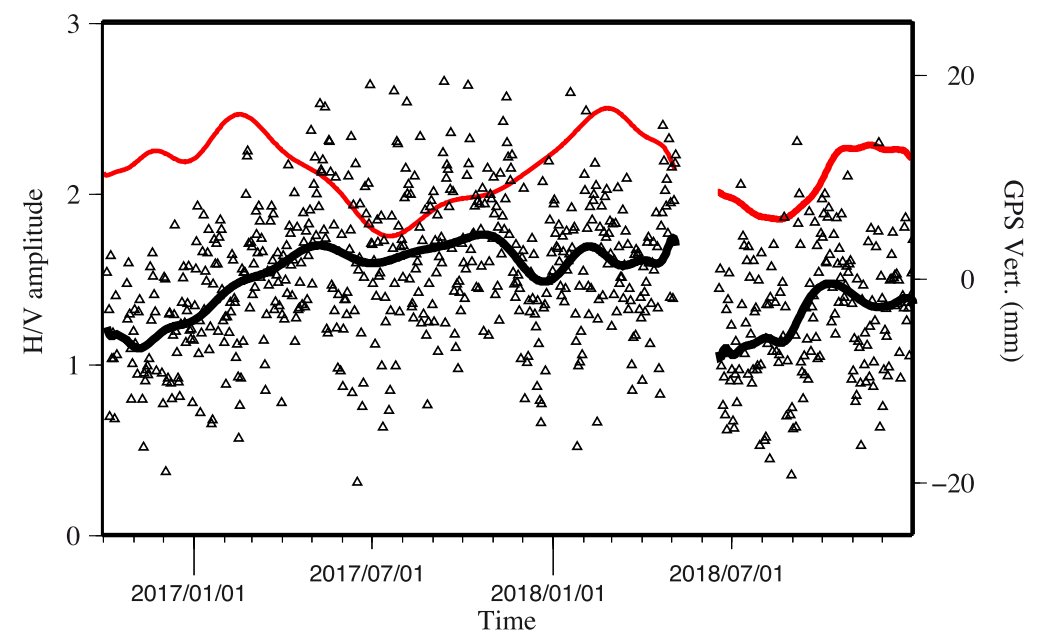

Figure 8. Temporal variations at station SS22. (a) Stacked time: red line: HVSR amplification peak amplitudes, thick black curve: GPS vertical coordinates observed at MESA, all filtered with a median sliding box of $30 \mathrm{~d}$ width. Normalized water level observations at wells F121A (stars), R122 (triangles), R122A (squares) and R134 (circles); grey area: water level envelope (see text for details). (b) Red line is the HVSR amplification peak amplitudes and in black is the GPS vertical coordinates at MESA (triangles), the applied filter for the curves is a median sliding box of $60 \mathrm{~d}$ width.

SS24 (Fig. 3), which are installed on Jurassic radiolarites of the Pindos zone and on Triassic breccias of the Ionian zone, respectively. Stations SS08 and SS24 are on the same Triassic cohesive breccias, but SS08 exhibits a narrower peak whose amplitude varies over time, while SS24 presents a wide peak. The difference of temporal behaviour between these two sites could be due to a more complex 3-D environment for SS24 (small hill surrounded by quaternary red clays and sand) and needs further investigation. SS19 is installed on Cretaceous limestone outcrop of the Pindos Zone, described as cavernous. Nevertheless, the HVSR curves exhibit two narrow peaks at around 3 and $5 \mathrm{~Hz}$ (Fig. 3), varying in time (Figs 4 and 7), and therefore absolutely not stable as expected. Both sites SS13 and SS22 are on folded flysch of the Gavrovo-Tripolis zone. There are fountains with continuous water flows close to them. Thus, it is evident for these two sites that water is abundant in the subsoil and can control the seismic wave velocities just below the seismological stations.

When a second peak exists as at stations SS08 and SS19, and if it does not correspond to higher mode of the first one, it is interpreted as an additional impedance contrast in the surficial sedimentary layer (Harutoonian et al. 2013). As we observed for the first peak
(P1), the second one (P2) has also the amplitude and the central frequency varying with time and following the same seasonal cycle with P1. In the case of SS19, P1 and P2 vary coherently in amplitude and in frequency, $\mathrm{P} 2$ at SS08 has its amplitude anti correlated with the one of $\mathrm{P} 1$, that is the amplitude of $\mathrm{P} 2$ is high in summer and low in winter, which may indicate an increase of the $S$-wave velocity at the deeper impedance contrast, but the frequencies vary similarly. Water saturation in subsurface shifts the peak frequency of the Rayleigh waves also in presence of body waves. Then, that is coherent with the seasonal variation of the peak frequency we observe. The depth of the impedance contrast is inversely proportional to the resonance frequency $f_{0}$. The estimates of the depths with the obtained $\mathrm{P} 1$ peak frequencies are from 20 to $150 \mathrm{~m}$, compatible with the known depths of water level.

We also observed that the amplitude of the peaks at all stations and the central frequency at station SS22 are more dispersed in winter than in summer, and in summer after a rainy event. Winter corresponds to the wettest period of the year with frequent precipitations. We suggest that this data dispersion is linked to the sensitivity of $V S$ to rainfall and soil moisture with possible variations from 5 to 20 per cent (Paoletti 2012; Wang et al. 2017; Clements \& 


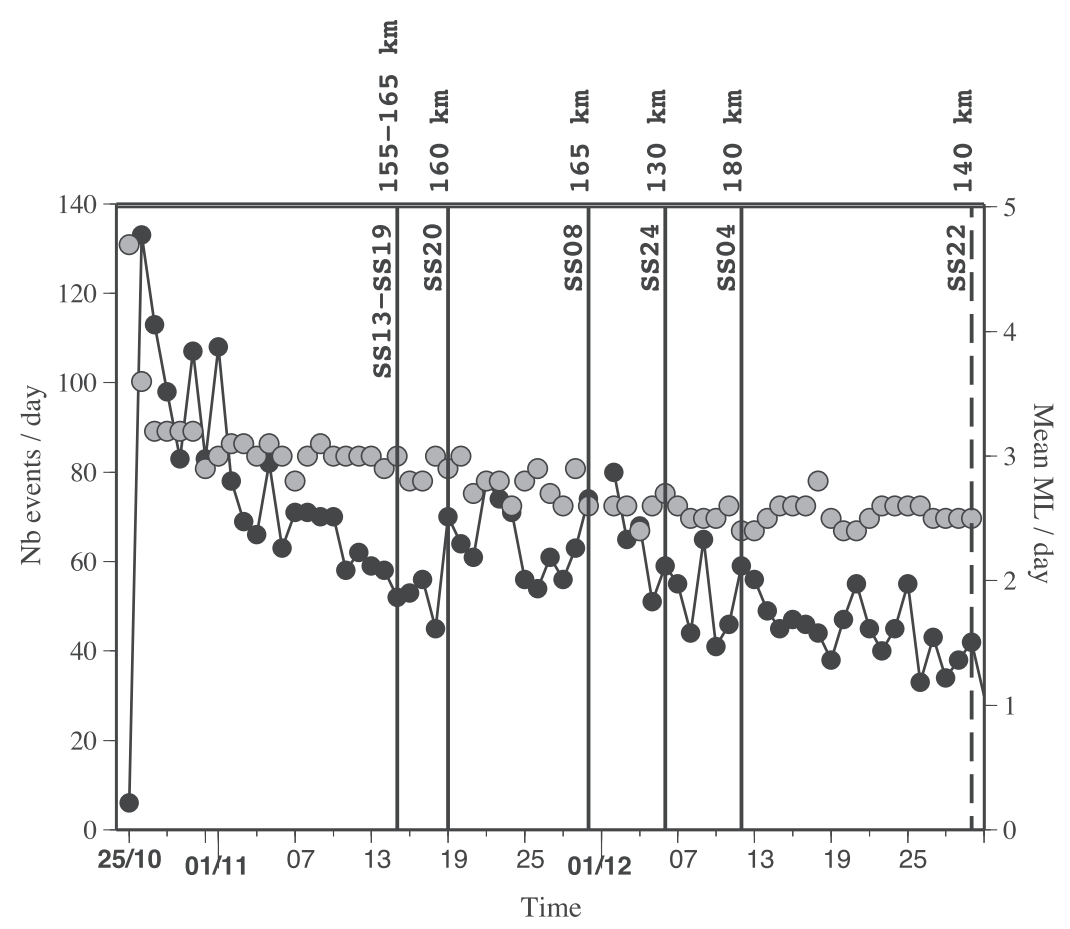

Figure 9. Aftershock sequence of Zakynthos seismic crisis from the NOA catalogue (http://bbnet.gein.noa.gr/HL/databases/database). Black circles: number of events per day; grey circles: mean magnitude ML per day; Vertical lines mark the day when the abnormal HVSR form stops at the indicated station and epicentral distances are also depicted vertically (except for SS22 (dashed), which stops after the 31/12/2018).

Table 1. Installation description, number $(\mathrm{Nr})$ of amplification peaks and their corresponding central frequency $f_{0}$, and the building configuration (Number ( $\mathrm{Nr}$ ) of floors) and frequency for each station of the network.

\begin{tabular}{|c|c|c|c|c|}
\hline Station & Installation type & $\mathrm{Nr}$ of peaks & $f_{0}(\mathrm{~Hz})$ & $\begin{array}{l}\mathrm{Nr} \text { of floors and building } \\
\text { frequency }\end{array}$ \\
\hline SS04 & Inside - Old school & 0 & - & $0-\geq 10 \mathrm{~Hz}$ \\
\hline SS08 & $\begin{array}{c}\text { Inside - Gymnasium of a } \\
\text { school }\end{array}$ & 2 & $5.6 / 7.6$ & $0-\geq 10 \mathrm{~Hz}$ \\
\hline SS09 & Outside-School & 0 & - & \\
\hline SS13 & $\begin{array}{c}\text { Inside - abandoned medical } \\
\text { centre }\end{array}$ & 3 & $2.8 / 3.4 / 8.3$ & $1-10 \mathrm{~Hz}$ \\
\hline SS17 & Outside-Old school & 1 & 5 & \\
\hline SS19 & Outside - Old school & 2 & $3.6 / 5$ & \\
\hline SS20 & Inside - Educational building & 1 & 1.5 to 4 & $2-5 \mathrm{~Hz}$ \\
\hline $\mathrm{SS} 21$ & $\begin{array}{l}\text { Outside_-Old municipal } \\
\text { building }\end{array}$ & 0 & - & \\
\hline SS22 & $\begin{array}{l}\text { Inside - Inactive municipal } \\
\text { building }\end{array}$ & 1 & 5.8 & $0-\geq 10 \mathrm{~Hz}$ \\
\hline SS24 & $\begin{array}{c}\text { Inside-Medical centre } \\
\text { (activity during a few hours } \\
\text { per month) }\end{array}$ & 1 & 1 to 4.5 & $0-\geq 10 \mathrm{~Hz}$ \\
\hline
\end{tabular}

Denolle 2018; Miao et al. 2018; Civilini et al. 2020; Roumelioti et al. 2020), even up to 40 per cent as observed in laboratory experiments (Irfan \& Uchimura 2013). At station SS08, but not at station SS19, this suggests that the second peak is less sensitive to rainfall and soil moisture, and therefore a more stable indicator of the aquifer condition. At station SS22, the water table is very near the surface, the central frequency is also affected by the rainy periods.

Regarding the change of the form of the HVSR curves following the occurrence of the Zakynthos earthquake, a possible explanation could be disturbances in groundwater levels or water content in the subsoil. Toutain et al. (2006), for example, have shown that microseismicity up to an epicentral distance of at least $10 \mathrm{~km}$ acts on the chemical composition of Pyrenean aquifers by modifying the amount of meteoric water. Moreover, Sanz de Ojeda et al. (2019) showed that most probably the 1750 Lisbonne earthquake induced hydrological phenomena disturbing the spring discharges all over the Iberian Peninsula. This specific case could be indicative that the mechanism causing the variation observed here is driven by changes in effective stresses due to pore pressure variations (Brodsky et al. 2003; Crane et al. 2013; Miao et al. 2018) maybe dynamically caused by the passage of the waves of the Zakynthos main shock.

The correlation between the variations of the loading and unloading cycle of the aquifers and the amplitudes of the peak of the HVSR curves could help to calibrate one with respect to the other. We showed that with a simple seismic signal processing without distinguishing the origin of the signal, it is possible to follow the 
state of the water content in the subsurface. However, this calibration is not possible here for two reasons: (i) the groundwater survey data are not all available with sufficient precision; and above all (ii) it is likely that the curves that we observed are not sensitive to only a single water table, but also to others around the station, given that the $\mathrm{H} / \mathrm{V}$ method is rather sensitive to surface waves which are coming from various azimuths (Cheng et al. 2020). This is visible with SS08 where the variations of the P1 amplitude are not exactly phased with the water level (Fig. 5b), SS08 being on the boundary of two different water tables according to HSGME. Thus, to validate such a technique for surveying the water table evolution, it is necessary to conduct a medium-term seismological experiment on a site where the geology of the first hundred meters, the precipitations and the aquifer parameters are very well known.

\section{ACKNOWLEDGEMENTS}

We are grateful to Nicos Germenis, Paris Paraskevopoulos, Dimitris Giannopoulos and George Andriopoulos for their help in the field; to HSGME for providing the monitoring data of the aquifers. We are particularly grateful to Samuel Bignardi, two anonymous reviewers, and the Editor Lapo Boschi for their relevant comments, which improved the manuscript. This work benefited from the support of INSU,CNRSTellus/Aleas 2016 and 2017. ES acknowledges financial support by the HELPOS project, 'Hellenic Plate Observing System' (MIS 5002697).

\section{REFERENCES}

Albarello, D. \& Lunedei, E., 2020. Structure of an ambient vibration wavefield in the frequency range of engineering interest $([0.5,20] \mathrm{Hz})$ : insights from numerical modelling, Near Surf. Geophys., 9, 543-559.

Bard, P.Y., 1998. Microtremor measurements: a tool for site effect estimation?, in Proceeding of the Second International Symposium on the Effects of Surface Geology on Seismic Motion, Yokohama, Japan, pp. 1251-1279.

Benjumea, B., Macau, A., Gabas, A., Bellmunt, F., Figueras, S. \& Cires, J., 2011. Integrated geophysical profiles and $\mathrm{H} / \mathrm{V}$ microtremor measurements for subsoil characterization, Surf. Geophys., 9, 413-425.

Bignardi, S., 2017. The uncertainty of estimating the thickness of soft sediments with the HVSR method: a computational point of view on weak lateral variations, J. appl. Geophys., 145, 28-38.

Bindi, D. et al., 2009. Site amplifications observed in the Gubbio Basin, Central Italy: hints for lateral propagation effects, Bull. seism. Soc. Am., 99, 741-760.

Bonilla, L.F., Steidl, J.H., Lindley, G.T., Tumarkin, A.G. \& Archuleta, R.J., 1997. Site amplification in the San Fernando Valley, California: variability of site-effect estimation using the S-wave, coda, and H/V methods, Bull. seism. Soc. Am., 87, 710-730.

Bonnefoy-Claudet, S., Cornou, C., Bard, P.-Y., Cotton, F., Moczo, P., Kristek, J. \& Fäh, D., 2006. H/V ratio: a tool for site effects evaluation. Results from 1-D noise simulations, Geophys. J. Int., 167, 827-837.

Bonnefoy-Claudet, S., Köhler, A., Cornou, C., Wathelet, M. \& Bard, P.-Y., 2008. Effects of love waves on microtremor H/V ratio, Bull. seism. Soc. Am., 98, 288-300.

Borges, J.F., Silva, H.G., Torres, R.J.G., Caldeira, B., Bezzeghoud, M., Furtado, J.A. \& Carvalho, J., 2016. Inversion of ambient seismic noise HVSR to evaluate velocity and structural models of the Lower Tagus Basin, Portugal, J. Seismol., 20, 875-887.

Brodsky, E.E., Roeloffs, E., Woodcock, D., Gall, I. \& Manga, M., 2003. A mechanism for sustained groundwater pressure changes induced by distant earthquakes, J. geophys. Res., 108, 2390. doi:10.1029/2002JB002321.

Burnol, A., Aochi, H., Raucoules, D., Veloso, F.M.L., Koudogbo, F.N., Fumagalli, A., Chiquet, P. \& Maisons, C., 2019. Wavelet-based analysis of ground deformation coupling satellite acquisitions (Sentinel-1, SMOS) and data from shallow and deep wells in Southwestern France, Sci. Rep., 9, 8812. doi:10.1038/s41598-019-45302-z.

Castellaro, S. \& Mulargia, F., 2009. VS30 estimates using constrained H/V measurements, Bull. seism. Soc. Am., 99, 761-773.

Chávez-García, F.J., Sanchez, L.R. \& Hatzfeld, D., 1996. Topographic site effects and HVSR. A comparison between observations and theory, Bull. seism. Soc. Am., 86, 1559-1573.

Chavez-Garcia, F.J. \& Faccioli, E., 2000. Complex site effects and building codes: making the leap, J. Seismol., 4, 23-40.

Cheng, T., Cox, B.R., Vantassel, J.P. \& Manuel, L., 2020. A statistical approach to account for azimuthal variability in single-station HVSR measurements, Geophys. J. Int., 223, 1040-1053.

Cipta, A., Cummins, P., Dettmer, J., Saygin, E., Irsyam, M., Rudyanto, A. \& Murjaya, J., 2018. Seismic velocity structure of the Jakarta Basin, Indonesia, using trans-dimensional Bayesian inversion of horizontal-tovertical spectral ratios, Geophys. J. Int., 215, 431-449.

Civilini, F., Savage, M.K. \& Townend, J., 2020. Shear wave velocity changes induced by earthquakes and rainfall at the Rotokawa and Ngatamariki geothermal fields, Taupo Volcanic Zone, New Zealand, Geophys. J. Int., 221, 97-114.

Clements, T. \& Denolle, M.A., 2018. Tracking groundwater levels using the ambient seismic field, Geophys. Res. Lett., 45, 6459-6465.

Cornou, C. \& Bard, P.-Y., 2003. Site-to-bedrock over 1D transfer function ratio: an indicator of the proportion of edge-generated surface waves?, Geophys. Res. Lett., 30, 1453. doi:10.1029/2002GL016593, 2003.

Cornou, C., Bard, P.Y. \& Dietrich, M., 2003. Contribution of dense array analysis to identification and quantification of basin-edge induced waves, part II: application to the Grenoble basin (French Alps), Bull. seism. Soc. Am., 93, 2624-2648.

Crane, J.M., Lorenzo, J.M., White, C.D. \& Shen, J., 2013. Seismic velocity prediction in shallow $(<30 \mathrm{~m})$ partially-saturated, unconsolidated sediments using effective medium theory, in Proceedings of the Symposium on the Application of Geophysics to Engineering and Environmental Problems. pp. 553-565. doi:10.4133/sageep2013-242.1.

Di Naccio, D., Vassallo, M., Di Giulio, G., Amoroso, S., Cantore, L., Hailemikael, S., Falcucci, E. \& Gori, S., 2017. Seismic amplification in a fractured rock site. The case study of San Gregorio (L'Aquila, Italy), Phys. Chem. Earth, 98, 90-216.

Fehr, M., Kremers, S. \& Fritschen, R., 2019. Characterisation of seismic site effects influenced by near-surface structures using 3D waveform modelling, J. Seismol., 23, 373-392.

Giannaraki, G., Kassaras, I., Roumelioti, Z., Kazantzidou-Firtinidou, D. \& Ganas, A., 2019. Deterministic seismic risk assessment in the city of Aigion (W. Corinth Gulf, Greece) and juxtaposition with real damage due to the 1995 Mw6.4 earthquake, Bull. Earthq. Eng., 17, 603-634.

Guéguen, P., Cornou, C., Garambois, S. \& Banton, J., 2007. On the limitation of the $\mathrm{H} / \mathrm{V}$ spectral ratio using seismic noise as an exploration tool: application to the Grenoble Valley (France), a small apex ratio basin, Pure appl. Geophys., 164, 115-134.

Harutoonian, P., Leo, C.J., Tokeshi, K., Doanh, T., Castellaro, S., Zou, J.J., Liyanapathirana, D.S. \& Wong, H., 2013. Investigation of dynamically compacted ground by HVSR-based approach, Soil Dyn. Earthq. Eng., 46, 20-29.

Haghshenas, E., Bard, P.-Y. \& Theodulidis, N. SESAME WP04 Team, 2008. Empirical evaluation of microtremor $\mathrm{H} / \mathrm{V}$ spectral ratio. Bull. Earthq. Eng., 6, 75-108.

Haskell, N.A., 1960. Crustal reflection of plane SH waves, J. geophys. Res., 65, 4147-4150.

Hinzen, K.-G., Weber, B. \& Scherbaum, F., 2004. On the resolution of H/V measurements to determine sediment thickness, a case study across a normal fault in the lower Rhine embayment, Germany, J. Earth. Eng., 8, 909-926.

Husen, S. \& Kissling, E., 2001. Postseismic fluid flow after the large subduction earthquake of Antofagasta, Chile, Geology, 29, $847-850$.

Irfan, M. \& Uchimura, T., 2013. Effects of soil moisture on shear and dilatational wave velocities measured in laboratory triaxial tests, in Proceedings of the 5th International Young Geotechnical Engineers' Conference 2013, 
eds, Cui, Y.-J., Emeriault, F., Cuira, F., Ghabezloo, S., Pereira, J.-M., Reboul, M., Ravel, H. \& Tang, A. M., IOS Press, pp. 505-509.

Lachet, C. \& Bard, P.Y., 1994. Numerical and theoretical investigations on the possibilities and limitations of Nakamura's technique, J. Phys. Earth, 42, 377-397.

Larochelle, S., Gualandi, A., Chanard, K. \& Avouac, J.-P., 2018. Identification and extraction of seasonal geodetic signals due to surface load variations, J. geophys. Res., 123, 11,031 11,047.

Laurendeau, A. et al., 2017. Seimic response of the basin of Quito from continuous accelerometric records of RENAC-QUITO, in Proceedings of the 16th World Conference on Earthquake, 16WCEE 2017, Santiago Chile. doi:S-I1464476619.

Lontsi, A.M. et al., 2019. A generalized theory for full microtremor horizontal-to-vertical $[\mathrm{H} / \mathrm{V}(\mathrm{z}, \mathrm{f})]$ spectral ratio interpretation in offshore and onshore environments, Geophys. J. Int., 218, 1276-1297.

Malagnini, L., Tricarico, P., Rovelli, A., Herrmann, R.B., Opice, S., Biella, G. \& De Franco, R., 1996. Explosion, earthquake, and ambient noise recording in a Pliocene sediment-filled valley : inferences on seismic response properties by reference- and non-reference-site techniques, Bull. seism. Soc. Am., 86, 670-682.

Malagnini, L., Dreger, D.S., Bürgmann, R., Munafo, I. \& Sebastiani, G., 2019. Modulation of seismic attenuation at Parkfield, before and after the 2004 M6 earthquake, J. geophys. Res., 124. doi:10.1029/2019JB017372.

Miao, Y., Shi, Y. \& Wang, Y., 2018. Temporal change of near surface shear wave velocity associated with rainfall in Northeast Honshu, Japan, Earth Planets Space, 70, 204. doi:10.1186/s40623-018-0969-3.

Moisidi, M., Vallianatos, F., Kershaw, S. \& Collins, P., 2015. Seismic site characterization of the Kastelli (Kissamos) Basin in northwest Crete (Greece): assessments using ambient noise recordings, Bull. Earthq. Eng., 13, 725-753.

Molnar, S. et al., 2018. Application of microtremor horizontal-to-vertical spectral ratio (MHVSR) analysis for site characterization: state of the art, Surv. Geophys., 39, 613-631.

Mucciarelli, M., 1998. Reliability and applicability of Nakamura's technique using microtremors: an experimental approach, J. Earthq. Eng., 2, 625638.

Mucciarelli, M., 2011. Ambient noise measurements following the 2011 Christchurch earthquake: relationships with previous microzonation studies, liquefaction, and nonlinearity, Seismol. Res. Lett., 82, 919-926.

Mucciarelli, M. \& Gallipoli, M.R., 2001. A critical review of 10 years of microtremor HVSR technique, Boll. Geofi. Teor. Ed Appl., 42, 255-266.

Mulargia, F. \& Castellaro, S., 2016. HVSR deep mapping tested down to $1.8 \mathrm{~km}$ in Po Plane Valley, Italy, Phys. Earth Planet Int., 261, 17-23.

Nakamura, Y., 1989. A method for dynamic characteristics estimation of subsurface using microtremor on the ground surface, Q. Rep. Railw. Tech. Res. Inst., 30, 25-33.

Nakamura, Y., 2019. What is the Nakamura method?, Seismol. Res. Lett., 90, 1437-1443.

Napolitano, F., Gervasi, A., La Rocca, M., Guerra, I. \& Scarpa, R., 2018. Site effects in the Pollino region from the HVSR and polarization of seismic noise and earthquakes, Bull. seism. Soc. Am., 108, 309-321.

Nur, A. \& Simmons, G., 1969. The effect of saturation on velocity in low porosity rocks, Earth planet. Sci. Lett., 7, 183-193.

Oliveto, A., Mucciarelli, M. \& Caputo, R., 2004. HVSR prospecting in multilayered environments: an example from the Tyrnavos Basin (Greece), $J$. Seismol., 8, 395-406.

Panzera, F., Romagnoli, G., Tortorici, G., D’Amico, S., Rizza, M. \& Catalano, S., 2019. Integrated use of ambient vibrations and geological methods for seismic microzonation, J. Appl. Geophys., 170, 103820. doi:10.1016/j.jappgeo.2019.103820.
Paoletti, V., 2012. Remarks on factors influencing shear wave velocities and their role in evaluating susceptibilities to earthquake-triggered slope instability: case study for the Campania area (Italy), Nat. Hazards Earth Syst. Sci., 12, 2147-2158.

Pérouse, E. et al., 2017. Transition from collision to subduction in Western Greece: the Katouna-Stamna active fault system and regional kinematics, Int. J. Earth Sci., 106, 967-989.

Rigo, A., Béthoux, N., Masson, F. \& Ritz, J.-F., 2008. Seismicity rate and wave-velocity variations as consequences of rainfall: the case of the catastrophic storm of September 2002 in the Nîmes Fault region (Gard, France), Geophys. J. Int., 173, 473-482.

Rigo, A., Béjar-Pizzaro, M. \& Martinez-Diaz, J.J., 2013. Monitoring of Guadalentin valley (southern Spain) through a fast SAR Interferometry method, J. appl. Geophys., 91, 39-48.

Roumelioti, Z., Hollender, F. \& Guéguen, P., 2020. Rainfall-Induced variation of seismic waves velocity in soil and implications for soil response: what the ARGONET (Cephalonia, Greece) vertical array data reveal, Bull. seism. Soc. Am., 110, 441-451.

Sanz de Ojeda, A., Alhama, I. \& Sanz, E., 2019. Aquifer sensitivity to earthquakes: the 1755 Lisbon Earthquake, J. geophys. Res., 124, 8844 8866.

Sarout, J., David, C. \& Pimienta, L., 2019. Seismic and microseismic signatures of fluids in rocks: bridging the scale gap, J. geophys. Res., 124. doi:10.1029/2019JB018115.

SESAME Project, 2004. Guidelines for the Implementation of the H/V Spectral Ratio Technique on Ambient Vibrations. Measurements, Processing and Interpretation. SESAME European Research Project WP12 - Deliverable D23-12.

Sivaram, K., Mahesh, P. \& Rai, S.S., 2012. Stability assessment and quantitative evaluation of $\mathrm{H} / \mathrm{V}$ spectral ratios for site response studies in Kumaon Himalaya, India Using Ambient Noise Recorded by a Broadband Seismograph Network, Pure appl. Geophys., 169, 1801-1820.

Souriau, A. et al., 2011. Multimethod characterization of the FrenchPyrenean Valley of Bagnères-de-Bigorre for seismic-hazard evaluation: observations and models, Bull. seism. Soc. Am., 101, 1912-1937.

Tarabusi, G. \& Caputo, R., 2017. The use of HVSR measurements for investigating buried tectonic structures: the Mirandola anticline, Northern Italy, as a case study, Int. J. Earth Sci., 106, 341-353.

Toutain, J.P., Munoz, M., Pinault, J.L., Levet, S., Sylvander, M., Rigo, A. \& Escalier, J., 2006. Using the mixing function to constrain co-seismic hydrochemical effects: an example from french pyrenees, Pure appl. Geophys., 163, 723-744.

Tranos, M.D., Weber, J.C., Bussey, J. \& O'Sullivan, P., 2020. Trichonis basin, western central Greece: is it an immature basin in the Corinth Rift or a pull-apart in a sinistral rift-trench link?, J. Geol. Soc., 177, 120-140.

Vassilakis, E., Royden, L.H. \& Papanikolaou, D.J., 2011. Kinematic links between subduction along the Hellenic trench and extension in the Gulf of Corinth, Greece: a multidisciplinary analysis, Earth planet. Sci. Lett., 303, 108-120.

Wang, Q.-Y., Brenguier, F., Campillo, M., Lecointre, A., Takeda, T. \& Aoki, Y., 2017. Seasonal crustal seismic velocity changes throughout Japan, $J$. geophys. Res., 122, 7987-8002.

Wathelet, M., Chatelain, J.-L., Cornou, C., Di Giulio, G., Guillier, B., Ohrnberger, M. \& Sawaidis, A., 2020. Geopsy: a user-friendly opensource tool set for ambient vibration processing, Seism. Res. Lett., 91, $1878-1889$.

Yassminh, R., Gallegos, A., Sandvol, E. \& Ni, J., 2019. Investigation of the regional site response in the Central and Eastern United States, Bull. seism. Soc. Am., 109, 1005-1024. 